

\section{Sumário}

Ordenamiento ambiental del terRitorio y participación CiUdadana en Argentina: aportes posibles DESDE EL DERECHO 2

María Valeria Berros

Matéria ambiental nos tribunais da Austrália e nova Zelândia ................................................... 17 Marcio Oliveira Portella

Conservação da BIODIVERSIDADE E POLÍtICAS PÚbLICAS PARA AS ÁREAS PROTEGIDAS NO BRASIL: DESAFIOS E

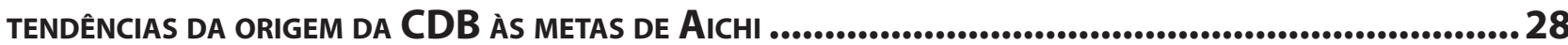

Ana Paula Leite Prates e Marta de Azevedo Irving

Dimensões linguísticas dA DESIGUALDADE No BrASIL: OS DIVERSOS NOMES LEGAIS DE UM MESMO FENÔMENo

Jefferson Carús Guedes

ECONOMIA, ÉTICA E TRIBUTAÇÃO: DOS FUNDAMENTOS DA DESIGUALDADE

Rafael Köche e Marciano Buffon

A REPARTIÇÃO de RENDAS ENTRE OS ENTES DA FEDERAÇÃO E SUA REPERCUSSÃo NA CARACTERIZAÇÃo DO FEDERALISMO BRASILEIRO: UMA INVESTIGAÇÃO ACERCA DO DESENVOLVIMENTO DO FEDERALISMO FISCAL-FINANCEIRO NO BRASIL.

Raquel Mousinho de Moura Fé

UMA AVALIAÇÃO DO ÍNDICE DE INCLUSÃO FINANCEIRA NOS ESTADOS DO NORDESTE BRASILEIRO

Diego Araujo Reis e Osvaldo Sousa Ventura

Fatores determinantes do Índice de Desenvolvimento Humano dos Municípios do Estado de São

PaUlo

Leandro Campi Prearo, Maria Clara Maraccini e Maria do Carmo Romeiro

As políticas públicas de acesso e difusão da cultura no Brasil e o caso do Programa Nacional de Apoio à Cultura. 157

Telma Rocha Lisowski

MoldANDO A "RESERVA do POSSível" NO TEMPO: A SUSTENTABILIDADE FISCAL COMO DIREITO DIFUSO FUNDAMENTAL. 171

Leonardo Romero Marino 
O PODER JUDICIÁRIO E A EFETIVAÇÃO DO DIREITO À SAÚDE

João Luis Nogueira Matias e Águeda Muniz

EDUCAÇÃo SUPERIOR NO BRASIL: OFERTA NA OMC, UMA REFLEXÃO DESMISTIFICADA, COM BASE EM DADOS ESTATÍSTICOS 208

Marcel Vitor Guerra

A GARANTIA DO DIREITO À EDUCAÇÃO DE CRIANÇAS E ADOLESCENTES NO CONTEXTO DAS POLÍTICAS PÚBLICAS BRASILEIRAS

André Viana Custódio e Rafael Bueno da Rosa Moreira

A POLÍCIA JUDICIÁRIA E O COMBATE À CRIMINALIDADE

Júlio Lopes Hott

Processo eleitoral e políticas Públicas: influÊnCias ReCíProcas.

Pablo Malheiros da Cunha Frota

SOCIEDADES PRIMITIVAS E DIREITO CONTEMPORÂNEO: DE QUE FORMA A JUSTIÇA TRIBAL PODE NOS AJUDAR A REPENSAR A NOSSA JUSTIÇA 303

Amanda Rodrigues e Tiago Themudo

DIREITO PRIVADO, JUSTIÇA DISTRIBUTIVA E O ARGUMENTO DA DUPLA DISTORÇÃO: UMA REVISÃO DA LITERATURA ...........318 Leandro Martins Zanitelli

DistorçõES NO CONTROLE CADASTRAL DAS ENTIDADES SINDICAIS E CONTRIBUIÇÃO SINDICAL Ricardo Bravo

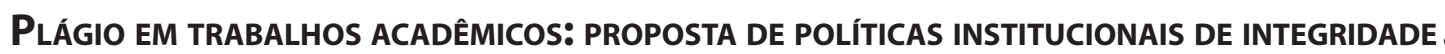
354 Maria Edelvacy Pinto Marinho e Marcelo Dias Varella 


\title{
Fatores determinantes do Índice de Desenvolvimento Humano dos Municípios do Estado de São Paulo*
}

\section{Factors affecting the Index Human Development of Municipalities of the State of São Paulo}

\author{
Leandro Campi Prearo** \\ Maria Clara Maraccini*** \\ Maria do Carmo Romeiro****
}

\section{Resumo}

Os quesitos qualidade de vida e bem-estar social estão em evidência nas discussões sobre desenvolvimento econômico. Nesse sentido, este estudo pretendeu avaliar o impacto dos gastos públicos municipais no Índice de Desenvolvimento Humano dos Municípios (IDHM) do Estado de São Paulo. Foram selecionadas rubricas de despesas públicas municipais para os anos de 2002 - 2010. A técnica estatística, para evidenciar tal impacto, foi a Análise Discriminante Múltipla, sendo a variável dependente o IDHM de 2010, categorizado em três grupos. As despesas com Saneamento, Assistência Social, Cultura, Educação e Urbanismo apresentaram-se estatisticamente significantes nessa relação, com destaque para Saneamento Básico como a mais importante.

Palavras-Chave: Gasto público. Desenvolvimento humano. IDHM. Gestão municipal.

* Recebido em 07/08/2014 Aprovado em 27/12/2014

** Doutor em Administração pela Universidade de São Paulo. Professor do Programa de Pós-Graduação Stricto Sensu em Administração da Universidade Municipal de São Caetano do Sul. Gestor do Instituto de Pesquisas da USCS. E-mail: leandro.prearo@uscs.edu. br

*** Graduada em Ciências Econômicas pela Universidade Municipal de São Caetano do Sul. E-mail: clarinha_maraccini@hotmail.com

**** Pró-reitora de Pós-Graduação e Pesquisa da USCS. Professora do Programa de PósGraduação Stricto Sensu em Administração da Universidade Municipal de São Caetano do Sul. E-mail: mromeiro@uscs.edu.br

\section{Abstract}

Questions the quality of life and social well-being are evident in discussions about economic development. Thus, this study sought to evaluate the impact of municipal public spending in the Human Development Index of Municipalities (IDHM) of the State of São Paulo. Items of municipal expenditure were selected for the years 2002 to 2010. A statistical technique to highlight the impact was the Multiple Discriminant Analysis, and the dependent variable IDHM 2010, categorized into three groups. Expenditure on Sanitation, Social Welfare, Education, Culture and Urbanism were statistically significant in this respect, especially Sanitation as the most important.

Keywords: Public Spending. Human development. IDHM. Municipal management. 


\section{INTRODUÇÃO}

Nos dias atuais, os quesitos qualidade de vida e bem-estar social estão em evidência nas discussões sobre desenvolvimento econômico. Conforme o paradoxo de Easterlin, uma vez que a riqueza atinge o nível de subsistência, a sua eficácia como um gerador de bem-estar diminui ${ }^{1}$. Por isso, diferente dos indicadores econômicos e sociais - como o Produto Interno Bruto (PIB) per capita, nível de desemprego, níveis de criminalidade - o conceito de desenvolvimento engloba a qualidade de vida da população, considerando-se indicadores como o IDH, Igualdade de Renda, Felicidade, Bem-Estar Subjetivo, Satisfação com a Vida, entre outros fatores que tornam a vida mais ou menos gratificante.

Para a realização de seus cálculos, o Índice de Desenvolvimento Humano (IDH) considera fatores como uma vida longa, acesso ao conhecimento e o padrão de vida de uma população, medindo assim, o progresso de uma nação a partir de três dimensões: renda, saúde e educação. De forma resumida, a renda é medida pela Renda Nacional Bruta per capita, a saúde pela expectativa de vida, e a educação, pela média de anos de educação de adultos e a expectativa de anos de escolaridade para crianças na idade de iniciar a vida escolar ${ }^{2}$.

Da mesma forma que os governos aplicam medidas sistemáticas em diversos aspectos da economia, alcançando desde a empregabilidade até taxas de poupança para o crescimento, eles também devem recolher uma variedade de medidas que reflitam avaliações subjetivas das vidas dos indivíduos para atingir percepções de desenvolvimento social. Além disso, esse conhecimento ajuda na educação de cidadãos sobre as escolhas que afetam suas vidas. Tal entendimento justifica-se no sentido de propiciar, por exemplo, aos administradores públicos, tomadas de decisão mais eficazes, uma vez que o bem-estar subjetivo pode completar as informações disponíveis e orientar políticas alternativas.

Nessa linha, muitos autores têm tratado de entender quais são os fatores determinantes das variações desses tipos de indicadores (como o IDH) nos municípios ou países, levando em consideração desde os investimentos públicos até a arrecadação das receitas municipais, cota-parte do ICMS, estabilidade macroeconômica e política, população, despesas com segurança nacional e segurança pública, com legislativo e judiciário, entre outros ${ }^{3}$.

Da contextualização apresentada, emerge o seguinte problema de pesquisa a ser analisado: quais os fatores determinantes para os níveis de desenvolvimento humano alcançados pelos municípios do Estado de São Paulo?

\subsection{Objetivo Geral}

Evidenciar os fatores determinantes para o crescimento do Índice de Desenvolvimento Humano nos municípios de São Paulo.

\subsection{Objetivos específicos}

Os objetivos específicos a serem alcançados no estudo são:

1 ANGELO, Lícia de Cerqueira et al. Fatores explicativos do Índice de Desenvolvimento Humano (IDH) para os municípios de Alagoas. Economia política do desenvolvimento, Maceió, v. 1, n. 6, p. 31-47, set./dez. 2009.

2 PROGRAMA DAS NAÇÕES UNIDAS PARA O DESENVOLVIMENTO. Atlas do desenvolvimento bumano dos municípios. Disponível em: <http://www.pnud.org.br/IDH/Default.aspx?indiceAccordion=1\&li=li_AtlasMunicipios>. Acesso em: 01 dez. 2013. 3 ALVES JÚNIOR, José A. O impacto das receitas no Índice de Desenvolvimento Humano (IDH) dos municípios do Estado do Ceará. 2004. 72 f. Dissertação (Mestrado) - Programa de pós-graduação em Economia, Faculdade de Economia, Universidade Federal do Ceará, Fortaleza, 2004; ADEYEMI, Sidikat L. et al. Determinants of human development in Sub-Saharan Africa. African Journal of Economic Policy, Africa, v. 13, n. 2, p. 15-34, dec. 2006. 
1. evidenciar os fatores determinantes dos Indicadores de Desenvolvimento Humanos mais presentes na literatura;

2. verificar o impacto dos fatores evidenciados no IDH dos municípios do Estado São Paulo.

\section{INDICADORES DE DESENVOLVIMENTO HUMANO}

\subsection{O Índice de Desenvolvimento Humano (IDH)}

Criado para oferecer um contraponto ao Produto Interno Bruto (PIB) per capita, que considera apenas a dimensão econômica do desenvolvimento, o Índice de Desenvolvimento Humano (IDH) foi desenvolvido pelo economista paquistanês Mahbub ul Haq, com a colaboração e inspiração do pensamento do economista Amartya Sen. Sua primeira apresentação aconteceu em 1990, no primeiro Relatório de Desenvolvimento Humano do Programa das Nações Unidas para o Desenvolvimento, agência líder da rede global de desenvolvimento da ONU, que trabalha principalmente pelo combate à pobreza e pelo Desenvolvimento Humano.

De acordo com o relatório divulgado pela PNUD, em 2012, a partir de dados do Censo 2010, o Brasil alcançou o $85^{\circ}$ lugar entre 187 países no ranking global de desenvolvimento humano, apresentando um índice de 0,730 , o que indica desaceleração no ritmo de expansão do país que durante a década de 2000, mostrou crescimento anual do IDH de $0,82 \%$ mas, entre o período de 2000 a 2010, 0,73\%.

Apesar de avanços, corrobora não tão significativos, o IDH brasileiro está abaixo da média da América Latina $(0,741)$ aparecendo atrás de países como Chile $(0,819)$, Argentina $(0,811)$, Uruguai $(0,792)$, Venezuela $(0,748)$ e Peru $(0,741)$.

Comparado com o BRICS, grupo de cooperação formado pelos países Brasil, Rússia, Índia, China e África do Sul, o Brasil assumiu o segundo lugar no ranking de IDH. O maior índice foi alcançado pela Rússia $(0,788)$.

O IDH é um índice-chave dos Objetivos do Desenvolvimento do Milênio das Nações Unidas e reúne três dos requisitos mais importantes para a expansão das liberdades das pessoas: a oportunidade de se levar uma vida longa e saudável — saúde — , ter acesso ao conhecimento — educação — e poder desfrutar de um padrão de vida digno - renda ${ }^{4}$.

$\mathrm{Na}$ dimensão longevidade, espera-se que o desenvolvimento humano aconteça a partir da redução da morte prematura e do acesso a saúde de qualidade para o alcance do mais alto padrão de saúde física e mental. A unidade de medida observada para cálculo da dimensão é a esperança de vida ao nascer.

$\mathrm{Na}$ dimensão educação, o desenvolvimento traz como objetivo principal o acesso ao conhecimento, que é visto como essencial para o bem-estar dos indivíduos por orientar as pessoas de modo que consigam tomar decisões sobre seus futuros. Para o cálculo dessa dimensão, são utilizadas duas variáveis: a média de anos de escolaridade e os anos de escolaridades esperados.

$\mathrm{Na}$ dimensão renda, observa-se o padrão de vida de uma sociedade. Por meio dela temos acesso às necessidades básicas e a possibilidade de escolhas genuínas de padrões de vida. Para mensurar a riqueza de uma nação, utiliza-se o indicador Renda Nacional per capita, no conceito da paridade do poder de compra.

A síntese das dimensões do índice é exemplificada na Figura 1.

4 PROGRAMA DAS NAÇÕES UNIDAS PARA O DESENVOLVIMENTO. O que é o IDHM. Disponível em: <http://www. pnud.org.br/IDH/IDHM.aspx?indiceAccordion=0\&li=li_IDHM>. Acesso em: 01 dez. 2013. 
Figura 1 - Dimensões do Índice de Desenvolvimento Humano

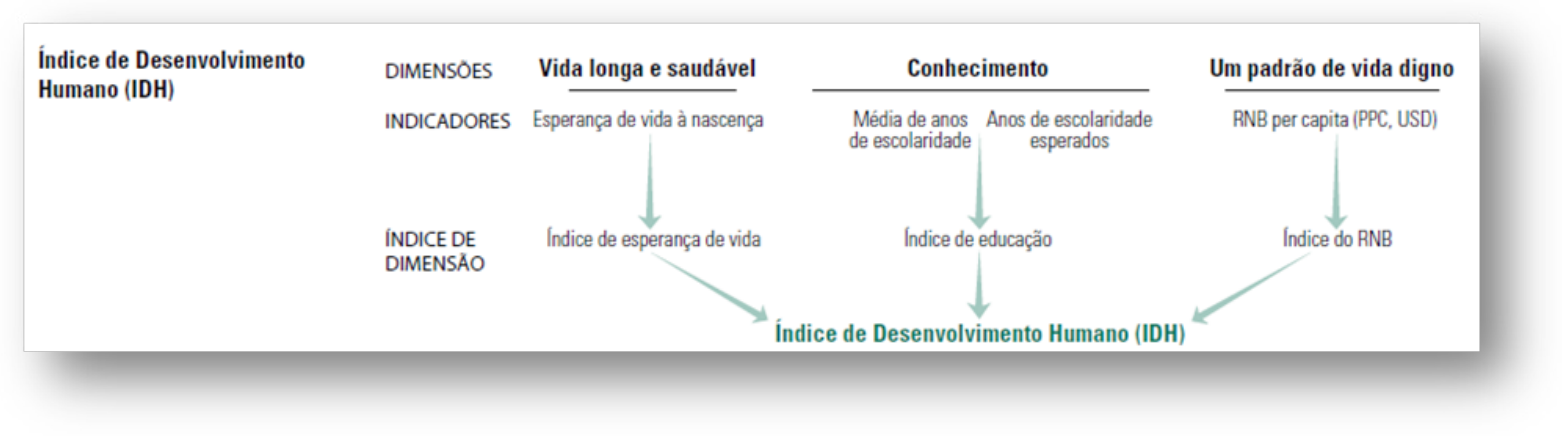

Fonte: Relatório do Desenvolvimento Humano ${ }^{5}$

O índice varia de 0 (zero) até 1 (um), sendo que 0 representa nenhum desenvolvimento humano e 1, desenvolvimento humano total. Nas publicações de 1991 e 2000, o IDH era classificado em baixo (até 0,499), médio (entre 0,500 e 0,799) e alto (acima de 0,800). Em 2010, houve uma modificação nos parâmetros que abrange essa escala, assim, a nova classificação para as pontuações é apresentada no Quadro 1.

Quadro 1 - Limites máximos e mínimos para a classificação do IDH

\begin{tabular}{|c|c|}
\hline Pontuação & Classificação \\
$0,800-1,000$ & Muito Alto \\
$0,700-0,799$ & Alto \\
$0,600-0,699$ & Médio \\
$0,500-0,599$ & Baixo \\
$0,000-0,499$ & Muito Baixo \\
\hline
\end{tabular}

Fonte: Do autor

A criação dos índices de dimensão é utilizada para transformar indicadores em índices que podem variar de 0 a 1. Para isso, são estipulados valores máximos e mínimos para cada variável sendo que os valores máximos são os mais altos observados no período e os mínimos, considerados como de subsistência: 20 anos para a dimensão longevidade (esperança de vida), 0 anos para a dimensão Educação (englobando as duas variáveis : média de anos de escolaridade e anos de escolaridade esperados) e USD 100 para a dimensão renda (variável rendimento nacional bruto - RNB), considerando-se a conceito de paridade do poder de compra (PPC) $)^{6}$.

Apesar de ainda ser pouco utilizado, o conceito da paridade do poder de compra (PPC), também conhecido como dólar internacional (I\$), aborda uma comparação mais realista sobre os preços dos produtos em cada país. Para isso, o Programa de Comparações Internacionais das Nações Unidas (iniciativa estatística mundial que utiliza a moeda como base de comparação entre os países) criou uma cesta única internacional de produtos e serviços e, periodicamente, analisa os preços e a composição de gastos apresentados por cada país e compara ao preço da mesma cesta em dólares americanos nos Estados Unidos, país de referência para a pesquisa. Dessa forma, a PPC pode ser utilizada como fator de conversão da moeda de um determinado país em dólares internacionais, a partir do cálculo: valor da cesta internacional em moeda local do país, dividido pelo valor da cesta internacional em dólares americanos

5 PROGRAMA DAS NAÇÕES UNIDAS PARA O DESENVOLVIMENTO. O que é o IDHM. Disponível em: <http://www. pnud.org.br/IDH/IDHM.aspx?indiceAccordion=0\&li=li_IDHM>. Acesso em: 01 dez. 2013.

6 PROGRAMA DAS NAÇÕES UNIDAS PARA O DESENVOLVIMENTO. O que é o IDHM. Disponível em: <http://www. pnud.org.br/IDH/IDHM.aspx?indiceAccordion=0\&li=li_IDHM>. Acesso em: 01 dez. 2013. 
Depois de estabelecidos os valores máximos e mínimos para cada indicador, calculam-se os subíndices pela razão:

\section{Índice de dimensão $=\frac{\text { valor observado }- \text { valor mínimo }}{\text { valor máximo }- \text { valor minimo }}$}

Como a dimensão Educação agrega duas variáveis (média dos anos de escolaridade e anos de estudo esperado), a equação apresentada é aplicada em cada variável. Para a obtenção da dimensão educação, considera-se, então, uma única medida, sendo que o valor mínimo é 0 e o máximo é a média geométrica mais elevada das duas variáveis. Feito isso, a equação é reaplicada à média geométrica dos índices, usando 0 como mínimo e a média geométrica mais elevada dos índices resultantes para o período sob análise como máximo?.

Ainda, é importante registrar que a variável renda é transformada em uma escala mais próxima das outras variáveis, a partir da utilização do logaritmo natural ${ }^{8}$.

Criados os índices das dimensões, eles são agregados para produzirem o Índice de Desenvolvimento Humano, por meio da média geométrica dos três índices de dimensão obtidos, conforme equação:

$$
I D H_{i}=\sqrt[3]{I D H_{\text {longevidade }_{i}} \times I D H_{\text {educação }}{ }_{i} \times I D H_{\text {renda }_{i}}}
$$

Apesar de ser o principal indicador para medir o nível de desenvolvimento de uma nação, o IDH recebeu muitas críticas ao longo desses 30 anos de publicação. Algumas delas, já foram incorporadas ao índice no Relatório de Desenvolvimento Humano publicado pelo PNUD em 2000, mas alguns questionamentos ainda perduram sobre o indicador. O IDH é criticado, por exemplo, por combinar variáveis como a alfabetização de adultos e expectativa de vida, que são estoques, com variáveis como a renda per capita anual e taxas brutas de alistamento escolar, que são fluxos. Além disso, observa-se que os dados medem esforços passados e não a situação presente. Sendo assim, os críticos afirmam que não fica clara a comparação dos rankings do PIB com os do IDH, já que o primeiro representa um fluxo e o último uma combinação de estoques e fluxos?.

Outra crítica nesta linha de raciocínio é de que índices econômicos e sociais não deveriam ser analisados em conjunto e sim, um após o outro ${ }^{10}$. Já Akder ${ }^{11}$, critica o fato do IDH não manifestar distinção por gênero, região, etnia, renda e ocupação, ele considera valores médios e é insensível à distribuição, consequentemente, dá abertura para a existência de disparidades.

Barros et al (2003) abordam como limitação do indicador, a falta de racionalidade na seleção dos indicadores que o compõem, visto que nada nas escolhas implícitas na construção do IDH garante que o índice

7 KILSZTAJN, Samuel. Paridade do poder de compra, renda per capita e outros indicadores econômicos. Revista Pesquisa e Debate, São Paulo, v. 11, n. 2, p. 93-106, 2000.

8 PROGRAMA DAS NAÇÕES UNIDAS PARA O DESENVOLVIMENTO. O que é o IDHM. Disponível em: <http://www. pnud.org.br/IDH/IDHM.aspx?indiceAccordion=0\&li=li_IDHM>. Acesso em: 01 dez. 2013.

9 HOPKINS, Michael. Human Development Revisited: a new UNDP report. World Development, v.19, n. 10, 1991; PYATT, Graham. There is nothing wrong with the HDI but. England: University of Warwick, 1992. IVANOVA, Ianita M. SRINIVASAN, G.; ARCELUS, F. J. A Quantitative measure of the competitive advantage of nations. New Brunswick: University of New Brunswick, 1994. (Working Paper Series, n. 94-008). IVANOVA, Ianita M.; ARCELUS, F. J.; SRINIVASAN, G. Effects of the buman development index's social and economic components of country rankings. New Brunswick: University of New Brunswick, 1994. EPHERENESIS, Dag. Policy uses of HDI: goals and strategies. SIDA: Planeringssekretariatet, 1994.

10 KANBUR, Ravi. Poverty and development. the human development report and the world development report 1990. Coventry: University of Warwick, 1990. (Discussion Paper, 103). PYAT'T, Graham. There is nothing wrong with the HDI but. Coventry: University of Warwick, 1992. RYTEN, Jacob. Should there be a buman development index. Montreux: Internacional Association for Official Statistics, sept. 2000.

11 AKDER, Halis. A means to closing gaps: disaggregated human development index, Human Development. New York: UNDP, 1994. (Report Office Occasional Papers, 18). 
represente uma considerável aproximação das preferências sociais. Abordam também a crítica de que o índice trata o desenvolvimento humano de forma simplificada, já que compila apenas três dimensões e quatro indicadores. Segundo os autores, as dimensões e os indicadores utilizados poderiam ser ampliados, mas a dificuldade está na confiabilidade e disponibilidade desses indicadores em atender os pressupostos de análise do IDH.

Ainda, segundo Barros12, a falta de agregabilidade do IDH impede a obtenção de uma média ponderada dos IDH's dos estados que o compõem. Isso acontece, pois vários dos indicadores adotados têm bases populacionais distintas (por exemplo a renda per capita do IDH é calculada utilizando toda a população, ao passo que a taxa de analfabetismo refere-se apenas à população de 15 anos e mais). Ademais, não há linearidade na elaboração do índice, mais especificamente na forma logarítmica como o indicador de disponibilidade de recursos utiliza a renda per capita. Como a soma dos logaritmos é distinta do logaritmo da soma, o componente de renda do IDH não é aditivamente agregável.

No Brasil, o Índice de Desenvolvimento Humano é mensurado para todos os municípios por meio do Índice de Desenvolvimento Humano Municipal (IDHM), o qual utilizada informações socioeconômicas sobre os municípios e estados do país e Distrito Federal e ainda que sutilmente difere de seu precedente nos métodos de cálculo.

\subsection{O Índice de Desenvolvimento Humano Municipal (IDHM)}

O Índice de Desenvolvimento Humano Municipal (IDHM) calcula o IDH Municipal dos 5.565 municípios do Brasil e, até hoje, teve três publicações por meio do Atlas de Desenvolvimento Humano que serve como uma plataforma de consulta ao índice. São responsáveis pela criação do indicador, três órgãos nacionais:

- Programa das Nações Unidas para o Desenvolvimento (PNUD): órgão global presente em 177 países e territórios ${ }^{13}$ que desenvolve projetos, objetivando contribuir com um crescimento que melhore a qualidade de vida de todos. É também responsável pela elaboração dos Atlas de Desenvolvimento Humano;

- Instituto de Pesquisa Econômica Aplicada (IPEA): órgão público federal que por meio de pesquisas, dá suporte às ações governamentais para modelagem de políticas públicas e programas de desenvolvimento;

- Fundação João Pinheiro: órgão público do governo de Minas Gerais, referência em pesquisas e informações socioeconômicas e demográficas.

A relevância de sua criação está no pressuposto de que, ao compararmos municípios brasileiros com um único número, o ranking do IDHM estimula formuladores e implementadores de políticas públicas em nível municipal, priorizando melhorias na vida das pessoas. O índice brasileiro compila as mesmas dimensões do IDH Global (longevidade, educação e renda) e ainda adequa a metodologia global para o contexto brasileiro devido à disponibilidade de indicadores nacionais (mais de 180 indicadores socioeconômicos) que ajudam na análise do IDHM e ampliam a compreensão dos fenômenos e dinâmicas voltados ao desenvolvimento municipal ${ }^{14}$.

12 BARROS, Ricardo Paes de et al. O Índice de Desenvolvimento da Família (IDF): Rio de Janeiro: IPEA, 2003. (Texto para discussão, 98).

13 PROGRAMA DAS NAÇÕES UNIDAS PARA O DESENVOLVIMENTO. Nosso trabalho. Disponível em: < http://www. pnud.org.br/NossosProjetos.aspx>. Acesso em: 01 dez. 2013.

14 PROGRAMA DAS NAÇÕES UNIDAS PARA O DESENVOLVIMENTO. Atlas do Desenvolvimento Humano, 2013. Disponível em: <http://www.pnud.org.br/IDH/EntendaAtlas.aspx?indiceAccordion=1\&li=li_Entenda>. Acesso em: 07 dez. 2013. 
O IDHM também tem uma escala que varia entre 0 (zero) até 1 (um), sendo que quanto mais próximo de 1, maior é o desenvolvimento humano do município. Seus parâmetros de classificação são os mesmos do IDH, classificado em muito alto, alto, médio, baixo e muito baixo, conforme Quadro 1.

Todas as fontes de informações são retiradas do Censo Demográfico do IBGE e, como dito anteriormente, a metodologia utilizada no cálculo do IDHM, difere em partes do IDH, conforme Quadro 2.

Quadro 2 - Indicadores utilizados: IDH versus IDHM

\begin{tabular}{|c|c|c|}
\hline \multirow{2}{*}{$\begin{array}{l}\text { ÍNDICE DE } \\
\text { DIMENSÃO }\end{array}$} & \multicolumn{2}{|c|}{ INDICADORES UTILIZADOS } \\
\hline & IDH & IDH-M \\
\hline Longevidade & Esperança de vida ao nascer & Esperança de vida ao nascer \\
\hline Renda & Renda Nacional per capita (PPC) & Renda Municipal per capita \\
\hline Educação & $\begin{array}{l}\text { - Média de anos de escolaridade } \\
\text { - Anos de escolaridade esperados }\end{array}$ & $\begin{array}{l}\text { - Escolaridade da população adulta } \\
\text { - Fluxo escolar da população jovem }\end{array}$ \\
\hline
\end{tabular}

Fonte: Do autor

Observa-se, no Quadro 2, a diferença nos indicadores utilizados nas dimensões Renda e Educação. A adoção da renda municipal per capita em substituição à renda nacional per capita dá maior realidade ao índice uma vez que considera a média mensal dos indivíduos residentes em determinado município, expressa em Reais. Já a dimensão Educação, apesar de ambos os índices considerarem indicadores que têm a mesma finalidade (situação educacional da população adulta e da população em idade escolar), as variáveis analisadas são diferentes, pois a média de anos de estudo de pessoas de 25 anos ou mais — variável utilizada pelo IDH - não é objeto de levantamento do Censo. Por esse motivo, o IDHM utiliza o percentual da população adulta de 18 anos ou mais que concluiu o ensino fundamental. Para medir a situação da população em idade escolar, o IDHM optou por medir, por meio de 4 indicadores, até que ponto as crianças e os jovens estão frequentando e complementando os ciclos escolares, resultando no subíndice fluxo escolar da população jovem. Essa adaptação trouxe maior confiabilidade ao indicador, uma vez que o IDH não considera tais ciclos, apenas mede a retenção das pessoas na escola, e inclui o ensino superior.

Outra diferença em relação aos dois índices é a fonte de dados utilizada para suas construções, motivo pelo qual não existe a possibilidade de comparação entre os mesmos. O IDH global traz dados do Departamento de Assuntos Econômicos e Sociais da Organização das Nações Unidas (ONU), Instituto de Estatísticas da UNESCO, Banco Mundial e Fundo Monetário Internacional, já o IDHM utiliza dados extraídos exclusivamente dos Censos Demográficos do IBGE ${ }^{15}$.

Para a dimensão Longevidade, o método utilizado é o mesmo do IDH Longevidade. A variável que compõe o índice é a esperança de vida ao nascer, que tem como objetivo considerar o nível e a estrutura de mortalidade de uma população. O valor máximo estabelecido para análise do subíndice é o maior observado no período. Já o valor mínimo utilizado difere de seu precedente e é, atualmente, de 25 anos de idade. Para o cálculo do índice, aplica-se a seguinte razão:

$$
\mathrm{IDH}-\mathrm{M} \text { Longevidade }=\frac{\text { valor observado }- \text { valor mínimo }}{\text { valor máximo - valor mínimo }}
$$

15 PROGRAMA DAS NAÇÕES UNIDAS PARA O DESENVOLVIMENTO. O que é o IDHM. Disponível em: <http://www. pnud.org.br/IDH/IDHM.aspx?indiceAccordion=0\&li=li_IDHM>. Acesso em: 07 dez. 2013. 
Já na dimensão renda, a variável que compõe o índice é a renda municipal per capita (renda média mensal dos indivíduos residentes em determinado município em reais). Os valores máximos e mínimos utilizados para padronização da variável no indicador que varia 0 e 1 são descritos conforme Quadro 3.

Quadro 3 - Valor máximo e mínimo estabelecidos para o IDHM Renda em 2010

\begin{tabular}{|c|cr|c|}
\hline Variável & \multicolumn{2}{|c|}{$\begin{array}{c}\text { Valor } \\
\text { estabelecido }\end{array}$} & Descrição \\
\hline Máximo & $\mathrm{R} \$ \quad 4.033,00$ & $\begin{array}{c}\text { Valor da menor renda per capita entre os 10\% mais ricos } \\
\text { residentes no país, com a menor renda média do país no período } \\
\text { analisado. }\end{array}$ \\
\hline Mínimo & $\mathrm{R} \$$ & 8,00 & $\begin{array}{c}\text { Aproximadamente US\$ } 100 \text { PPC, limite adotado para o cálculo } \\
\text { do IDH Global. }\end{array}$ \\
\hline
\end{tabular}

Fonte: Atlas do Desenvolvimento Humano ${ }^{16}$

Os valores utilizados para cálculo são obtidos das respostas ao questionário da amostra do Censo Demográfico e chega-se a um único valor por meio da razão entre o somatório de todos os rendimentos dos indivíduos residentes no município e o número total desses indivíduos. Com a variável em mãos, aplica-se a equação:

$$
\mathrm{IDH}-\mathrm{M} \text { Renda }=\frac{\ln (\text { renda } \text { per capita } \text { municipal })-\ln (\text { valor mínimo })}{\ln (\text { valor máximo })-\ln (\text { valor mínimo })}
$$

É importante lembrar que, ao aplicar o logaritmo à fórmula, a escala de valores é significativamente menor, tornando as variações mais lineares. Ao utilizar tal procedimento, deve-se considerar que, a medida que a renda per capita se eleva, o retorno desse acréscimo de renda, em termos de desenvolvimento humano, diminui. ${ }^{17}$

Uma das críticas considerada como limitação desse indicador é o fato de não considerar a desigualdade de renda entre os habitantes do município em função do uso da média de renda, a qual pode ser inapropriada em amostras com grande variação, caso típico do estudo da renda. Sendo assim, pode haver disparidades entre a renda dos habitantes, uma vez que o município atinge uma elevada renda per capita, mas com grande parte de sua população vivendo na pobreza.

A dimensão Educação do IDHM é a que mais difere em termos conceituais e metodológicos do IDH e sofreu modificações ao longo desses anos de publicação. O IDHM Educação é composto por dois indicadores: escolaridade da população adulta, que é medida pelo percentual de pessoas com 18 anos ou mais de idade com o ensino fundamental completo e, fluxo escolar da população jovem, medido pela média aritmética do percentual de crianças entre 5 a 6 anos de idade que frequentam a escola, de jovens de 11 a 13 anos que frequentam os anos finais do Ensino Fundamental, de jovens de 15 a 17 anos com Ensino Fundamental completo e de jovens de 18 a 20 anos de idade com o ensino médio completo. Tais indicadores também são obtidos de acordo com as respostas obtidas no questionário da amostra do Censo Demográfico do IBGE ${ }^{18}$.

Para o cálculo do IDHM Educação, são utilizados parâmetros, como ilustra o Quadro 4, e, para transformá-los em um índice que varie de 0 a 1, divide-se a taxa por 100.

16 PROGRAMA DAS NAÇÕES UNIDAS PARA O DESENVOLVIMENTO. Atlas do Desenvolvimento Humano dos Municípios. Disponível em: <http://www.pnud.org.br/IDH/Default.aspx?indiceAccordion=1\&li=li_AtlasMunicipios>. Acesso em: 01 dez. 2013

17 PROGRAMA DAS NAÇÕES UNIDAS PARA O DESENVOLVIMENTO. O que é o IDHM. Disponível em: < http:// www.pnud.org.br/IDH/IDHM.aspx?indiceAccordion=0\&li=li_IDHM>. Acesso em: 07 dez. 2013.

18 PROGRAMA DAS NAÇÕES UNIDAS PARA O DESENVOLVIMENTO. Atlas do Desenvolvimento Humano. 2013. Disponível em: <http://www.pnud.org.br/IDH/EntendaAtlas.aspx?indiceAccordion=1\&li=li_Entenda>. Acesso em: 07 dez. 2013. 
Quadro 4 - Valor máximo e mínimo estabelecidos para os subíndices do IDHM Educação em 2010

\begin{tabular}{|c|c|c|}
\hline Descrição & Valor mínimo estabelecido & Valor máximo estabelecido \\
\hline Taxas de frequência & $0 \%$ & $100 \%$ \\
\hline Taxas de conclusão & $0 \%$ & $100 \%$ \\
\hline
\end{tabular}

Fonte: Do autor ${ }^{19}$

Após encontrado o valor índice de cada variável, o IDHM Educação é calculado a partir da média geométrica dos dois índices, considerando-se que o índice de escolaridade tem peso 1 e o índice de fluxo tem peso 2, como mostra a figura 2 .

Figura 2 - Equações utilizadas para cálculo do IDHM Educação

$$
\text { Índice de escolaridade da população adulta }=\frac{\sum \text { taxas de frequência }}{100}
$$

Índice de fluxo escolar da população jovem $=\frac{(\text { subindice } 1+\text { subindice } 2+\text { subindice } 3+\text { subindice } 4)}{4}$

IDH-M Educação $=\sqrt[3]{\text { índice de escolaridade } \times \text { índice de fluxo } \times \text { índice de fluxo }}$

Fonte: Do autor

Como dito anteriormente, o indicador Educação sofreu alterações em sua metodologia. Isso aconteceu em 2013, tornando-o mais rigoroso ao exigir maior grau de escolaridade para que o município atinja um maior IDHM. Em duas de suas publicações (1998 e 2003), as variáveis consideradas para cálculo do indicador eram taxa de alfabetização de pessoas acima de 15 anos de idade e taxa bruta de frequência escolar. $\mathrm{Na}$ mais recente atualização publicada em 2013, o IDHM Educação é formado pelos subíndices: escolaridade da população adulta, que é medida pelo percentual de pessoas com 18 anos ou mais de idade com o Ensino Fundamental completo e fluxo escolar da população jovem, medido pela média aritmética do percentual de crianças entre 5 a 6 anos de idade que frequentam a escola, de jovens de 11 a 13 anos que frequentam os anos finais do ensino fundamental, de jovens de 15 a 17 anos com ensino fundamental completo e de jovens de 18 a 20 anos de idade com o ensino médio completo. Síntese das mudanças é apresentada no Quadro 5.

19 O índice de escolaridade da população adulta é calculado a partir da razão do somatório das taxas de frequência por 100. Já o índice de fluxo escolar da população jovem é encontrado por meio da soma dos subíndices obtidos, dividida pelo número de subíndices. PROGRAMA DAS NAÇÕES UNIDAS PARA O DESENVOLVIMENTO. Atlas do Desenvolvimento Humano. 2013. Disponível em: <http://www.pnud.org.br/IDH/EntendaAtlas.aspx?indiceAccordion=1\&li=li_Entenda>. Acesso em: 07 dez. 2013. 


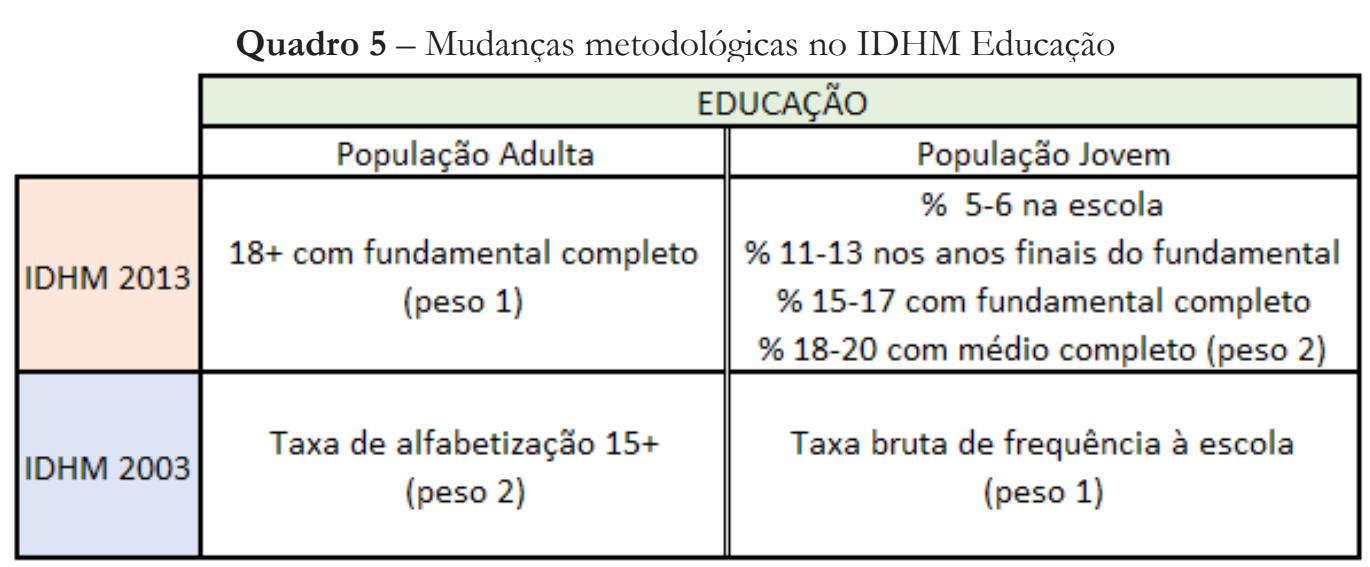

Fonte: Do autor

Assim como o IDHM Longevidade, o indicador Educação também se depara com algumas limitações. Pode-se observar que a medida da educação população jovem não capta toda a passagem do jovem pelo sistema educacional, considerando-se apenas momentos e parte da população escolar. Além disso, estabelece também, uma faixa etária ampliada da ideal para essa população, por razões estatísticas. Já a medida da educação da população adulta considera apenas pessoas que completaram o Ensino Fundamental, deixando de lado aqueles que, apesar de não completarem o ciclo, tiveram passagens nele.

Após calculados todos os índices de dimensão, chegamos ao IDHM por meio da média geométrica dos 3 índices encontrados:

\section{IDHM $_{i}=\sqrt[3]{\text { IDHMlongevidade }_{i} \times \text { IDHMeducação }_{i} \times \text { IDHMrenda }_{i}}$}

\section{Determinantes do desenvolvimento humano}

Para avaliar os possíveis determinantes dos Índices de Desenvolvimento Humano, foram levantadas 11 publicações, sendo 6 em periódicos nacionais e 5 em periódicos internacionais dos últimos 16 anos (1997 2013) - todos classificados no sistemas Qualis/CAPES, que estudaram quantitativamente as relações entre um conjunto de variáveis e os indicadores de desenvolvimento humano.

A partir da análise do referencial teórico, verificou-se a frequência com que cada variável independente (determinantes) apareceu nos estudos. Os resultados são apresentados na Tabela 1.

Tabela 1 - Presença das variáveis independentes no referencial teórico (em porcentagem)

\begin{tabular}{|cc}
\hline VARIÁVEL & PRESENÇA NO \\
INDEPENDENTE & REFERENCIAL \\
\hline Despesas públicas & $36 \%$ \\
\hline PIB per capita & $36 \%$ \\
\hline Receitas públicas & $36 \%$ \\
\hline Informações sobre população & $27 \%$ \\
Necessidades básicas & $18 \%$ \\
Variáveis dummies & $18 \%$ \\
\hline Dados macroeconômicos & $9 \%$ \\
Renda & $9 \%$ \\
\hline
\end{tabular}

Fonte: Do autor

$$
\text { Renda }
$$


Conforme ilustrado na Tabela 1, as variáveis que apresentaram maior frequência nos estudos são as despesas públicas, o PIB per capita e as receitas públicas.

Nesse sentido, essas variáveis foram consideradas para um maior aprofundamento de sua utilização em tais estudos:

- PIB per capita: dentro das 11 publicações analisadas, 4 delas apresentaram como variável independente o PIB per capita;

- Swaha e Tondo ${ }^{20}$ testaram a correlação do PIB como variável independente com o IDH (variável dependente) em seu estudo "Equilíbrio entre Desenvolvimento Humano e Crescimento Econômico: um estudo da ASEAN 5" e constataram que não há nenhuma significância entre as variáveis. Já Kurt e Savrul ${ }^{21}$ realizaram um estudo que analisava 10 países da União Europeia em um período de 10 anos a fim de verificar o efeito do Bloco no Desenvolvimento Humano. Utilizaram uma variável dummy e o PIB per capita como variáveis independentes e o IDH 2004 como dependente. Por meio da regressão, constataram que existe significância entre todas as variáveis, ou seja, o PIB per capita explica parte do IDH 2004. Receitas públicas: as receitas públicas também apareceram em 36\% do referencial teórico como variável independente.

Alves ${ }^{22}$, estudou "O impacto das receitas no Índice de Desenvolvimento Humano (IDH) dos municípios do Estado do Ceará", analisou 184 municípios cearenses dentro de um período de 5 anos. Como variável independente, Alves levou em consideração a arrecadação total das receitas municipais que abrange as receitas municipais próprias, transferências e operações de crédito de 1995 a 1999 e como dependente, o IDH 2000. Nesse estudo, concluiu-se que a variável é significante e, portanto, tem participação do IDH 2000 do Estado do Ceará.

Silva et al23 em seu estudo "A influência do desempenho tributário e gestão fiscal no Índice Firjan de Desenvolvimento Municipal (IFDM) dos municípios de Minas Gerais” analisaram 796 municípios mineiros no período de um ano. Os métodos utilizados foram a análise de cluster e regressão logística que testaram as variáveis independentes: Fundo de Participação dos Municípios (FPM), Cota-Parte do ICMS, IPTU, ITBI, ISS, taxas que estão englobadas no conceito de tributo comum, receita orçamentária, Índice Firjan de Gestão Fiscal e Índice Firjan de Desenvolvimento Social, sendo todos os valores per capita junto à duas variáveis dependentes: IFDM 2010 e IFGF 2010. O resultado do estudo apresentou significância em todas as variáveis, mostrando que todas têm relação com os índices mencionados como dependentes. Em outro estudo realizado por Farina, Gouvêa e Varela ${ }^{24}$ foi analisada "A diferenciação dos Grupos 2 e 5 de municípios paulistas, segundo o IPRS, a partir das transferências constitucionais e das receitas tributárias: uma aplicação de análise discriminante". O Índice Paulista de Responsabilidade Social classifica os municípios em Grupos de 1 a 5, de acordo com seus indicadores de riqueza, longevidade e escolaridade. Os autores estudaram os grupos 2 e 5 do IPRS com abrangência na capital e municípios do interior de São Paulo. Por meio da análise discriminante, foram relacionadas as variáveis independentes: FPM per capita, cota-parte do ICMS per capita

20 SHOME, Swaha; TONDON, Sakira. Balancing human development with economic growth: a study of ASEAN 5. Annals of the University of Petrosani, Petroșani, v. 10, n. 2, p. 335-348, 2010.

21 KURT, Serdar; SAVRUL, Mesut. The effect of the European Union on human development. International Research Journal of Finance and Economics, United Kingdom, v. 65, p. 35-42, 2011.

22 ALVES JÚNIOR, José A. O impacto das receitas no Índice de Desenvolvimento Humano (IDH) dos municípios do Estado do Ceará. 2004. 72 f. Dissertação (Mestrado) - Programa de pós-graduação em Economia, Faculdade de Economia, Universidade Federal do Ceará, Fortaleza. 2004.

23 SILVA, Lara Lúcia da, et al. A influência do desempenho tributário e gestão fiscal no Índice Firjan de Desenvolvimento (IFDM) dos municípios de Minas Gerais. Revista de Ciências Humanas, Viçosa, v. 13, n. 1, p. 199- 219, jan./jun. 2013.

24 FARINA, Milton Carlos; GOUVÊA, Maria Aparecida; VARELA, Patrícia Siqueira. A diferenciação dos Grupos 2 e 5 de municípios paulistas, segundo o IPRS, a partir das transferências constitucionais e das receitas tributárias: uma aplicação de análise discriminante. Revista Contemporânea de Economia e Gestão, Fortaleza, v. 5, n. 1, p. 17-28, jan./jul. 2007. 
e receita tributária per capita com os Grupos 2 e 5 do IPRS (variáveis dependentes). Verificou-se no estudo que há significância apenas entre a variável independente receita per capita, ou seja, ela mantém relação com os Grupos em questão.

- Despesas públicas: essa variável apareceu em 4 das 11 publicações presentes no referencial teórico e mostrou significância em todas as análises selecionadas.

Roque et a $\mathbb{P}^{5}$ estudaram a relação das despesas públicas com o IDHM. A análise abrangeu 287 municípios baianos no período de 10 anos e concluiu por meio da regressão linear múltipla que as variáveis: Despesas com planejamento, despesas com indústria e comércio, despesas com educação e cultura, despesas com habitação e urbanismo e despesas judiciárias são significantes e portanto, mantém relação com o IDHM da Bahia.

Rezende et al26, por meio da análise de cluster e regressão logística, verificaram em seu estudo que as variáveis despesa corrente total de 1991 - 2000 e despesa de capital total de 1991 - 2000 apresentaram relação com a variável dependente IDH 1991, porém não foi possível diagnosticar quais têm mais significância com os investimentos públicos.

Razmi $e$ t a ${ }^{27}$ estudaram o Irã em um período de 19 anos, a fim de verificar se há relação das despesas com saúde pública do país e seu IDH. Na publicação "Investigação do efeito das despesas de saúde do Governo sobre o IDH no Irã”, concluiu-se que existe relação entre as variáveis, ou seja, as despesas com saúde pública no Irã interferem no IDH do país.

Ramirez28, realizaram uma análise que dividia as variáveis independentes em duas cadeias: "A" que considera: PIB per capita (1960 - 70); despesas sociais (despesa pública com educação e saúde) como porcentagem do PIB; e cadeia “B” que leva em consideração as variáveis: log do PIB per capita em 1960; log expectativa de vida (1967); nível de alfabetização de adultos (1970 - 72) e Investimento Interno Bruto como porcentagem do PIB $(1960$ - 92). Tais variáveis independentes foram testadas com duas variáveis dependentes que são: redução do déficit de expectativa de vida $(1970$ - 92) e PIB per capita $(1970$ - 92) por meio do método dos Mínimos Quadrados Ordinários (Regressão Linear Múltipla).

O estudo analisou um período de 32 anos e uma amostra de 35 dos 76 países que estão em desenvolvimento e constatou que todas as variáveis apresentaram influência na expectativa de vida e no PIB per capita.

\section{Aspectos metodológicos}

Uma das formas de se analisar o desempenho dos municípios é avaliar o caráter de seus gastos, que refletem-se na realização de investimentos. Nesse estudo pretende-se avaliar a influência que as despesas municipais têm em cada grupo de classificação do IDHM visto que o objetivo é verificar valores significativos e não baixas variações.

Foram escolhidas como variáveis independentes algumas despesas públicas do Estado de São Paulo, de acordo com a Fundação SEADE, a saber:

25 SANTOS, Manuel Roque Dos; DIAS, José Maria; FERNANDES, Gilênio Borges. Avaliação da Capacidade de Predição de Índice de Desenvolvimento Humano dos Municípios (IDHM) a partir das Demonstrações Contábeis Legais. In: ENCONTRO DA ANPAD, 34., 2010, Rio de Janeiro. Anais...Rio de Janeiro: ANPAD, 2010. p. 1-17.

26 REZENDE, Amaury José; SLOMSKI, Valmor; CORRAR, Luiz João. A gestão pública municipal e a eficiência dos gastos públicos: uma investigação empírica entre as políticas públicas e o Índice de Desenvolvimento Humano (IDH) dos municípios do Estado de São Paulo. Revista Universo Contábil, Blumenau, v. 1, n. 1, p. 24-40, jan./abr. 2005.

27 RAZMI, Mohammad Javad; ABBASIAN, Ezatollah; MOHAMMADI, Sahar. Investigating the effect of government health expenditure on HDI in Iran. Journal of Knowledge Management, Economics and Information Technology, Iran, v. 5, p. 119-131, oct. 2012.

28 RAMIREZ, Alejandro; RANIS, Gustav; STEWART, Frances. Economic growth and buman development. New Haven: Yale University, dec. 1997. (Center Discussion Paper, n. 787). 
- Despesa com Assistência Social: esta variável contempla as despesas realizadas pelo Poder Público Municipal decorrentes das ações voltadas ao bem-estar social. Fazem parte das Contas de Despesa em Assistência Social: a Assistência ao Idoso, Assistência ao Portador de Deficiência, Assistência à Criança e ao Adolescente e Assistência Comunitária;

- Despesa com Desporto e Lazer: são as despesas realizadas pelo Poder Público Municipal decorrentes das ações voltadas ao desporto e lazer. Fazem parte das Contas da Despesa em Desporto e Lazer: o Desporto de Rendimento, Desporto Comunitário e o Lazer;

- Despesa com Cultura: despesas realizadas pelo Poder Público Municipal decorrentes das ações que visam o desenvolvimento, difusão e preservação de conhecimento adquirido e acumulado pela comunidade. Fazem parte das Contas da Despesa em Cultura: o Patrimônio Histórico, Artístico e Arqueológico e a Difusão Cultural;

- Despesa com Educação: são despesas realizadas pelo Poder Público Municipal, decorrentes das ações voltadas à Educação e fazem parte da Conta da Despesa em Educação: o Ensino Fundamental, Médio, Profissional e Superior, Educação Infantil, Educação de Jovens e Adultos e Educação Especial;

- Despesa com Urbanismo: essa variável contempla as despesas realizadas pelo Poder Público Municipal decorrentes das ações voltadas ao Urbanismo. Fazem parte da Conta da Despesa em Urbanismo: a Infraestrutura Urbana, Serviços Urbanos e Transportes Coletivos Urbanos;

- Despesa com Investimentos: Despesas realizadas pelo Poder Público Municipal no planejamento e execução de obras e complementos a elas necessários. A Conta da Despesa em Urbanismo é composta por: Transferências, Obras e Instalações, Equipamentos e Material Permanente, Sentenças Judiciárias, Despesas de Exercícios Anteriores e Indenizações e Restituições;

- Despesa com Saúde: despesas realizadas pelo Poder Público Municipal decorrentes das ações desenvolvidas no sentido da promoção, proteção, recuperação e reabilitação da saúde. Fazem parte dessa conta as variáveis: Atenção Básica, Assistência Hospitalar e Ambulatorial, Suporte Profilático e Terapêutico, Vigilância Sanitária, Vigilância Epidemiológica e Alimentação e Nutrição;

- Despesa com Saneamento: são despesas realizadas pelo Poder Público Municipal, decorrentes das ações que visam o fornecimento de água de boa qualidade às populações, o destino final dos esgotos domésticos e despejos industriais e a melhoria das condiçõesanitárias das comunidades. Fazem parte da Conta da Despesa em Saneamento as variáveis: Saneamento Básico Rural e Saneamento Básico $\mathrm{Urbano}^{29}$.

Como já citado, o Índice de Desenvolvimento Humano Municipal classifica o desenvolvimento dos municípios em cinco categorias: Muito Alto, Alto, Médio, Baixo e Muito Baixo. Posto isso, após a seleção dos dados do Estado de São Paulo, verificou-se grande homogeneidade nos índices, os quais concentram-se quase que exclusivamente no conceito "alto". Partindo-se dessa observação, para a aplicação da técnica estatística multivariada de Análise Discriminante Múltipla, foi proposta uma nova junção dos grupos a partir do uso dos quartis (Tabela 2), visto que pretende-se discriminar apenas as grandes variações.

Para tanto, foi escolhida a análise discriminante como técnica estatística a ser utilizada, uma vez que é apropriada quando tem-se uma variável categórica (nominal ou não métrica) como dependente e variáveis métricas como independentes. É comum na análise discriminante, a variável dependente consistir em dois grupos ou classificações como alto versus baixo, ou então, em grupos múltiplos como as classificações em

29 FUNDAÇÃO SEADE. Seade 35 anos: estatísticas públicas para o desenvolvimento do estado de São Paulo. Disponível em: <http://www.seade.gov.br/wp-content/uploads/2014/12/Seade-35-anos-PDF.pdf>. Acesso em: 01 dez. 2013. 
baixo, médio e alto. Para esse segundo caso, a técnica é chamada de análise discriminante múltipla (MDA), que será utilizada no presente estudo.

Ainda, para melhor discriminar os fatores que influenciam no IDHM, foram introduzidos no modelo apenas os municípios presentes nos extremos, ou seja, $1^{\circ}$ quartil, que considera municípios com desenvolvimento de 0,000 a 0,718 e $4^{\circ}$ quartil, que abrange os municípios classificados de 0,761 a 1,000 ponto.

Tabela 2 - Nova junção dos grupos a partir do uso de quartis

\begin{tabular}{c|c}
\hline \multicolumn{2}{c}{ CLASSIFICAÇÃO DAS VARIÁVEIS } \\
INDEPENDENTES \\
\hline $1^{\circ}$ Quartil & 0,000 a 0,718 \\
$2^{\circ}$ Quartil & 0,719 a 0,737 \\
$3^{\circ}$ Quartil & 0,738 a 0,760 \\
$4^{\circ}$ Quartil & 0,761 a 1,000 \\
\hline
\end{tabular}

Fonte: Do autor

Para aplicação da análisediscriminante, constrói-se um modelo composto por seis estágios, a saber:

- Estágio 1: definição do problema de pesquisa e seleção dos objetivos a serem alcançados ao aplicar a técnica;

- Estágio 2: seleção das variáveis e definição de qual deve ser a dependente e quais as independentes, o tamanho da amostra e a divisão da mesma para fins de validação;

- Estágio 3: verificação de premissas obrigatórias (ver Tabela 3) que a função discriminante deve atender para a aplicação ser apropriada;

- Estágio 4: decisão do método de estimação e do número de funções a ser retido. Depois selecionam-se as variáveis independentes com maior poder de discriminação e não correlacionadas entre si (método Stepwise);

- Estágio 5: consiste na interpretação dos resultados por meio do exame das funções discriminantes para determinar a importância relativa de cada variável independente na discriminação entre os grupos. Para tanto, utilizam-se três métodos que determinam sua importância relativa: (1) pesos discriminantes padronizados, (2) cargas discriminantes (correlações de estrutura) e (3) valores $F$ parciais;

- Estágio 6: validação dos resultados discriminantes para garantir que tenham validade interna e externa. É utilizado o método de validação cruzada e o perfil de grupos para garantir que as médias de grupos sejam indicadores válidos do modelo conceitual usado na seleção de variáveis independentes. 
A Tabela 3 mostra as premissas para aplicação da técnica utilizada.

Tabela 3 - Premissas para a aplicação da análise discriminante30

\begin{tabular}{l|l}
\hline \multicolumn{1}{c|}{ Premissas subjacentes } & \multicolumn{1}{c}{ Considerações' } \\
\hline Tamanho da amostra & $\begin{array}{l}\text { Idealmente 20, mas no mínimo } 5 \text { casos para cada va- } \\
\text { riável preditora } \\
3 \text { ou } 5 \text { vezes o número de variáveis independentes }\end{array}$ \\
\hline Homoscedasticidade & Box’M >0,05 \\
\hline Linearidade & $\begin{array}{l}\text { Condição para que os testes de significância sejam váli- } \\
\text { dos }\end{array}$ \\
\hline Normalidade multivariada & \\
\hline Ausência de Multicolinearidade & \\
\hline Ausência de observações atípicas & Cada grupo deve ter no mínimo 20 observações \\
\hline Tamanho dos grupos
\end{tabular}

\section{Resultados}

Este capítulo está organizado da seguinte forma: o item 5.1 trata dos resultados gerais da amostra, evidenciando as estatísticas descritivas dos investimentos, por meio das quais avalia-se a média, mediana, coeficiente de variação e variação no período de cada variável estudada. O item 5.2 mostra os resultados da análise discriminante múltipla. Tal item contempla as verificações das premissas de aplicação da técnica estatística e os resultados encontrados a partir delas.

\subsection{Resultados gerais da amostra}

A Tabela 4 ilustra as estatísticas descritivas das despesas estaduais, permitindo algumas análises parciais.

De acordo com os valores médios encontrados, conclui-se que a variável Despesa com Educação é que a recebe maior investimento per capita ( $\mathrm{R} \$ 608,96)$, seguida da Despesa com Saúde $(\mathrm{R} \$ 477,13)$ e Despesa com Urbanismo ( $\mathrm{R} \$ 277,94)$. Tais resultados apontam que, dentre as despesas públicas selecionadas para o estudo, são com estas variáveis que os municípios têm maior preocupação. Os valores medianos indicam qual é a metade dos investimentos realizados para cada variável, ou seja, metade dos municípios investem abaixo da mediana e a outra metade, acima da mediana.

A partir dos coeficientes de variação encontrados, verifica-se que há grande heterogeneidade no estado de São Paulo, ou seja, há muitos municípios investindo muito e muitos municípios investindo muito pouco. Atenta-se para a variável Despesa com Saneamento, que apresentou maior coeficiente de variação (129,74\%), o que permite supor que há elevada disparidade entre os investimentos dos municípios. A variável menos heterogênea do estudo é Despesa com Educação, que apresentou um coeficiente de variação de $42 \%$. A partir do dado, observa-se uma inclinação positiva na curva de investimento dos municípios, podendo-se sugerir que é uma variável mais influente do que as demais e que talvez, indispensável de se investir.

Analisando o período de 2002 a 2010, observou-se que os municípios passaram a investir mais em Cultura, Desporto e Lazer e Saúde. A Despesa com Saneamento foi a que apresentou menor variação de crescimento — apenas 15,45\% — o que não mostra grandes intenções de investimento por parte dos municípios.

30 PREARO, Leandro Campi. Os serviços públicos e o bem-estar subjetivo da população: uma modelagem multigrupos baseada em mínimos quadrados parciais. 2013. 257 f. Tese (Doutorado) - Programa de Pós-graduação em Economia, Faculdade de Economia, Administração e Contabilidade, Universidade de São Paulo, São Paulo, 2013. 
Tabela 4 - Estatísticas descritivas dos investimentos de forma geral

\begin{tabular}{l|c|c|c|c}
\hline \multicolumn{1}{c|}{ Item } & Média & Mediana & $\begin{array}{c}\text { Coeficiente de } \\
\text { variação }\end{array}$ & $\begin{array}{c}\text { Variação 2002- } \\
2010\end{array}$ \\
\hline Assistência Social & 102,29 & 82,21 & 73,64 & 30,45 \\
\hline Desporto e Lazer & 40,69 & 29,67 & 88,94 & 67,95 \\
\hline Cultura & 19,67 & 14,26 & 114,84 & 157,33 \\
\hline Educação & 608,96 & 566,70 & 42,00 & 42,35 \\
\hline Urbanismo & 277,94 & 237,00 & 63,80 & 33,56 \\
\hline Investimentos & 275,36 & 222,84 & 72,59 & 33,76 \\
\hline Saneamento & 55,06 & 11,08 & 129,74 & 15,45 \\
\hline Saúde & 477,13 & 422,82 & 42,64 & 54,18 \\
\hline
\end{tabular}

Fonte: Do autor

\subsection{Resultados da Análise Discriminante Múltipla}

A primeira fase na aplicação da Análise Discriminante Múltipla foi a verificação dos atendimentos às premissas da técnica (tamanho da amostra e divisão da amostra, homocedasticidade, normalidade multivariada, multicolinearidade e tamanho dos grupos).

- Tamanho da amostra e divisão da amostra: na técnica aplicada é ideal obter-se uma proporção de 20 observações para cada variável preditora. Sendo assim, o estudo compreende 39 observações para cada variável preditora (312 casos para 8 preditoras), respeitando a premissa do tamanho da amostra. Em relação à divisão da amostra, é estabelecido que no mínimo, o menor grupo deve exceder ao número de variáveis independentes. No presente estudo, o menor grupo (Grupo 2, com 150 observações) excede o número de variáveis independentes (8) em até 18 vezes;

- Homoscedasticidade: de acordo com o teste Box's M, ilustrado na Tabela 5, pretende-se aceitar a hipótese de homogeneidade das variâncias. Nesse estudo, houve rejeição da hipótese nula, sugerindo um modelo com heteroscedasticidade. Não obstante, ainda que com consciência da problemática, esta não será tratada nesse estudo.

Tabela 5 - Resultados do Teste Box's M

\begin{tabular}{c|c}
\hline Box's M & $\mathbf{2 2 3 , 0 6 2}$ \\
\hline F Approx. & 14,631 \\
\hline Df1 & 15 \\
\hline Df2 & 439443,302 \\
\hline Sig. &, 000 \\
\hline
\end{tabular}

Fonte: Do autor

- Normalidade Multivariada: segundo Prearo ${ }^{31}$, a distribuição normal multivariada tem a forma de sinos tridimensionais simétricos na seguinte situação: o eixo de x apresenta valores de uma determinada variável, o eixo de y apresenta a contagem para cada valor da variável de $\mathrm{x}$ e, o eixo de z mostrar os valores de qualquer outra variável em consideração. É uma condição fundamental de aplicação nas técnicas estatísticas de análise multivariada entretanto, Johnson e Wichern30 alertam que, para dados reais, a presença de variáveis com distribuição normal multivariada exata é difícil de se encontrar.

31 PREARO, Leandro Campi. Os serviços públicos e o bem-estar subjetivo da população: uma modelagem multigrupos baseada em mínimos quadrados parciais. 2013. 257 f. Tese (Doutorado) - Programa de Pós-graduação em Economia, Faculdade de Economia, Administração e Contabilidade, Universidade de São Paulo, São Paulo, 2013. 
Assim, a densidade normal é geralmente uma aproximação eficaz à verdadeira distribuição da população. Nesse estudo, a premissa de normalidade multivariada não foi verificada;

- Multicolinearidade: no presente estudo, fez-se uso do método Stepwise, o qual não exige atendimento à premissa de multicolinearidade, já que só são incluídas no modelo as médias de cada variável apresentada. De acordo com Hair et al32, para a realização do método Stepwise escolhe-se a melhor variável discriminatória e faz-se pares com cada uma das outras variáveis independentes a fim de verificar qual a variável que, em combinação com a primeira, irá melhorar o poder de discriminação da função. No decorrer desse processo, à medida que são incluídas variáveis adicionais, outras podem ser excluídas se apresentarem informações já existentes em combinações das outras variáveis incluídas em estágios posteriores da aplicação.

- O Stepwise é apresentado como um método eficaz quando tem-se um número relativamente grande de variáveis independentes para inclusão na função. O objetivo é selecionar as melhores variáveis discriminatórias em cada passo e eliminar as que não são úteis na discriminação.

- Tamanho dos grupos: para atender tal premissa, cada grupo deve ter no mínimo 20 observações. Nesse estudo, os grupos 1 e 2 são formados por 162 e 150 observações, respectivamente.

Atendidas as premissas, a Tabela 6 apresenta os valores médios das despesas em cada grupo do período de 2002 a 2010, bem como teste F para verificação de suas diferenças. Assim, os resultados iniciais sugerem poder discriminante das variáveis Assistência Social, Cultura, Educação e Saneamento. Para as variáveis Desporto e Lazer, Urbanismo, Investimento e Saúde, as diferenças de investimentos entre os Grupos não são aplicáveis, visto que as mesmas não são estatisticamente significantes. Verificando as médias de investimentos de cada Grupo, comparados à média total, chegou-se a algumas conclusões:

- O Grupo 1 - municípios com IDHM de até 0,718 — apresentou investimento acima da média na variável Despesa com Assistência Social (R $\$$ 111,29 per capita). Já o Grupo 2, dos municípios com maior desenvolvimento humano (de 0,761 a 1,000) investiram $\mathrm{R} \$ 79,16$ per capita, 28,9\% a menos. Supõe-se que municípios menos desenvolvidos têm maior carência em programas de ordem social e por isso, maior necessidade em preocupar-se com esses gastos;

- Para a variável Despesa com Cultura, observa-se exatamente o contrário: municípios classificados com alto grau de desenvolvimento tendem a investir mais ( $\mathrm{R} \$ 25,46$ per capita, 27,2\% acima da média), contra $\mathrm{R} \$ 14,80$ investidos pelo Grupo 1. Os dados permitem sugerir que a variável não é prioridade de investimento dos municípios menos desenvolvidos e que o gasto com cultura pode ser característico de municípios com alto grau de desenvolvimento, que têm maior poder de investimento para assuntos de segunda ordem de prioridade;

- A variável Despesa com Educação, assim como Despesa com Assistência Social, mostra que o Grupo 1 investe um percentual maior que o Grupo 2 e que talvez, tenha maiores gastos em pilares sociais básicos. Municípios com menor desenvolvimento geralmente têm carências básicas, estas que já foram superadas por municípios com alto grau de desenvolvimento e tendem a investir mais em pilares sociais, de importância principal para o desenvolvimento de sua população. O Grupo 1 apresentou investimento de 6,6\% acima da média e, 14,5\% acima do Grupo 2, que investe $\mathrm{R} \$ 563,43$ per capita, $6,9 \%$ abaixo da média total;

- Atenta-se à variável Despesa com Saneamento que, assim como a Despesa com Cultura, recebe maiores investimentos do Grupo 2 porém, em uma quantidade muito acima da média. Os municípios mais desenvolvidos, investem $\mathrm{R} \$ 87,65$ per capita contra $\mathrm{R} \$$ 57,00 da média total e R \$27,62 dos Grupo 1, ou

32 HAIR JÚNIOR, J. F. et al. Análise multivariada de dados. 5. ed. Porto Alegre: Bookman, 2005. 
seja 53,8\% e 217,3\% a mais, respectivamente. O investimento em Saneamento melhora a qualidade de vida da população e de acordo com os dados, é levado muito em conta no Grupo 2. O fato pode ser explicado por meio da hipótese que municípios mais desenvolvidos têm maior verba para tal, visto que é um investimento caro e necessita certo grau de urbanização e desenvolvimento no município.

Tabela 6 - Estatísticas descritivas das variáveis independentes

\begin{tabular}{c|c|c|c|c}
\hline TIPO DE DESPESA & \multicolumn{1}{|c|}{ TOTAL } & GRUPO 1 & GRUPO 2 & SIGNIFICÂNCIA \\
\hline Assistência Social & 95,57 & 111,29 & 79,16 & 0,000 \\
Desporto e Lazer & 36,72 & 35,72 & 37,75 & 0,560 \\
Cultura & 20,02 & 14,80 & 25,46 & 0,000 \\
Educação & 605,13 & 645,11 & 563,43 & 0,006 \\
Urbanismo & 268,37 & 251,85 & 285,59 & 0,116 \\
Investimento & 265,63 & 271,28 & 259,74 & 0,616 \\
Saúde & 470,28 & 474,52 & 465,87 & 0,694 \\
Saneamento & 57,00 & 27,62 & 87,65 & 0,000 \\
\hline
\end{tabular}

Fonte: Do autor.

Após concluir que quatro das variáveis têm diferenças estatisticamente significantes, isoladamente, avaliou-se por meio do Teste Lambda de Wilks as oito variáveis simultaneamente para verificar seus graus de diferenciação nos grupos. No teste, espera-se rejeitar a hipótese nula de que as variáveis são iguais entre os grupos, obtendo Lambda menor que um e ainda, quanto menor for seu valor, mais significativa será a variável. Constata-se assim, na Tabela 7, que a um nível de 1\% de significância, rejeita-se a hipótese nula, ou seja, o teste foi significativo para as variáveis Despesa com Assistência Social, Cultura, Educação, Saneamento e Urbanismo.

Tabela 7 - Resultado da estatística Wilks'Lambda

\begin{tabular}{c|c|c}
\hline TIPO DE DESPESA & ESTATÍSTICA WILKS'LAMBDA & SIGNIFICÂNCIA \\
\hline Saneamento & 0,858 & $\mathrm{p}<0,01$ \\
\hline Assistência Social & 0,826 & $\mathrm{p}<0,01$ \\
\hline Cultura & 0,779 & $\mathrm{p}<0,01$ \\
\hline Educação & 0,749 & $\mathrm{p}<0,01$ \\
\hline Urbanismo & 0,713 & $\mathrm{p}<0,01$ \\
\hline Fonte: Do autor &
\end{tabular}

A título ilustrativo, a tabela 8 apresenta as funções de Fischer para cada grupo estudado. Segundo Hair et a ${ }^{\beta}$, novos casos inseridos na amostra (nesse caso, municípios) teriam suas características de despesa inseridas nas equações e o maior dos resultados apontaria para o grupo de classificação daquele município.

Tabela 8 - Resultados da Função de Fisher

\begin{tabular}{lcc}
\hline \multicolumn{1}{c}{ TIPO DE DESPESA } & GRUPO 1 & GRUPO 2 \\
\hline Constante & $-4,269$ & $-3,517$ \\
Assistência Social & 0,011 & 0,002 \\
Cultura & $-0,038$ & $-0,012$ \\
Educação & 0,012 & 0,008 \\
Urbanismo & $-0,005$ & $-0,001$ \\
Saneamento & 0,005 & 0,015 \\
\hline G1 = - 4,269 + 0,011AS - 0,038CULT + 0,012EDU - 0,005URB + 0,005SAN \\
\hline G2 = - 3,517+0,002AS - 0,012CULT + 0,008EDU - 0,001URB + 0,015SAN
\end{tabular}

33 HAIR JÚNIOR, J. F. et al. Análise multivariada de dados. 5. ed. Porto Alegre: Bookman, 2005. 
Por meio da classificação dos resultados apresentada na Tabela 9, observa-se que o modelo estimado apresenta 72,9\% de acerto para Grupo 1; 69,3\% para o Grupo 2 e 71,2\% no agregado dos dois grupos.

Tabela 9 - Classificação dos Resultados

\begin{tabular}{|c|c|c|c|c|}
\hline & \multirow{2}{*}{ MODELO } & \multicolumn{2}{|c|}{ Participação no grupo previsto } & \multirow{2}{*}{ Total } \\
\hline & & 1,00 & 2,00 & \\
\hline & $\begin{array}{l}\text { Contagem original } \\
1,00\end{array}$ & 124 & 46 & 170 \\
\hline & 2,00 & 50 & 113 & 163 \\
\hline & Casos não agrupados & 162 & 150 & 312 \\
\hline$\%$ & 1,00 & 72,9 & 27,1 & 100,0 \\
\hline & 2,00 & 30,7 & 69,3 & 100,0 \\
\hline & Casos não agrupados & 51,9 & 48,1 & 100,0 \\
\hline
\end{tabular}

$171,2 \%$ dos casos originais agrupados e classificados corretamente Fonte: Do autor

\subsection{Avaliação do ajuste geral}

A avaliação do ajuste geral do modelo foi realizada a partir do Critério de Chance Proporcional e da Estatística Q de Press, conforme sugestão de Hair et al34.

- Critério de chance proporcional

O critério de chance proporcional representa o percentual de acerto se todas as observações fossem colocadas no grupo que apresenta maior probabilidade de ocorrência. Avalia-se por meio da equação:

$$
\begin{aligned}
& \text { Cpro }=p^{2}+(1-p)^{2} \\
& \text { Cpro }=0,511^{2}+(0,489)^{2} \\
& \text { Cpro }=0,5002
\end{aligned}
$$

Ao resultado de Cpro deve ser acrescentado 20\%, pois a precisão de classificação deve ser no mínimo um quarto maior do que a obtida por chances, então:

$$
0,5002 * 1,25=60
$$

De acordo com o resultado obtido, pode-se afirmar que, no critério de chances, o modelo apresenta $60 \%$ de possibilidade de acerto. Já no modelo proveniente desse estudo, alcança-se $71,2 \%$ de acerto, o que o torna melhor e mais adequado perante a um teste de tentativa e erro.

- Estatística Q de Press

Esse teste estatístico tem por objetivo medir o poder discriminatório da matriz de classificação quando esta é comparada com um modelo de chances como o Cpro, por exemplo. Obtém-se pela fórmula:

$$
\begin{aligned}
& \text { Q de Press }=\frac{\left[N-(n \times K){ }^{2}\right]}{N(K-1)} \\
& Q \text { de Press }=\frac{\left[312-(237 \times 2)^{2}\right]}{312(2-1)} \\
& Q \text { de Press }=719,12
\end{aligned}
$$

A estatística Q de Press mostrou que, a 1\% de significância, considerando-se um valor crítico de 395,96, as previsões do modelo desenvolvido são significantemente melhores do que chances.

34 HAIR JÚNIOR, J. F. et al. Análise multivariada de dados. 5. ed. Porto Alegre: Bookman, 2005. 


\section{Conclusão}

Foi proposto, no presente estudo, evidenciar quais os fatores que mais discriminam o Índice de Desenvolvimento Humano dos municípios do estado de São Paulo. Primeiramente, foram selecionados 11 estudos dos últimos 16 anos (1997 - 2013) para buscar o estado da arte dos estudos dos determinantes do Desenvolvimento Humano. Após esta etapa, objetivou-se desenvolver um modelo de determinantes do Desenvolvimento Humano para os municípios do estado de São Paulo, considerando as despesas públicas como objeto de estudo.

Por meio da técnica estatística de análise discriminante múltipla, constatou-se que as variáveis Despesa com Assistência Social, Despesa com Cultura, Despesa com Educação, Despesa com Saneamento e Despesa com Urbanismo são estatisticamente significantes, ou seja, surtem algum efeito sobre o IDHM.

De acordo com as observações, analisou-se que os municípios com menor desenvolvimento, pertencentes ao Grupo 1 (IDHM até 0,718) tendem a investir mais em pilares sociais básicos como Assistência Social e Educação. Tal fato pode ser explicado pela hipótese de que estes necessitam voltar sua atenção primeiramente à sua população, para assim conseguirem crescer em outros setores.

Verificou-se também que municípios com alto grau de desenvolvimento apresentam maiores gastos em Saneamento e Cultura. Supõe-se assim que tais cidades já apresentam certo nível de urbanização, o que permite o investimento em infraestrutura e no desenvolvimento da população residente. $\mathrm{O}$ alto investimento em saneamento, por exemplo, pode ser explicado pelo gasto com manutenção e reformas em seus sistemas de instalação. O investimento nesse setor contempla uma minoria do Estado. Tal fato se evidencia na Tabela 4, na qual observa-se o alto coeficiente de variação da variável $(129,74)$ e concluem-se algumas observações de acordo com dados retirados do Governo.

De acordo com o Instituto Federal Trata Brasil ${ }^{35}$, o atendimento de coleta de esgotos chega a apenas 48,1\% da população brasileira, ou seja, menos da metade da população do país. Baseando-se nesse cenário, conclui-se que a maioria dos municípios não realiza o investimento e, consequentemente, apresentam condições precárias nesse setor. De acordo com a última Pesquisa Nacional de Saneamento Básico ${ }^{36}$, dentre os 645 municípios do Estado, apenas 93 unidades participam do consórcio Inter municipal/Inter federativo na área do setor de saneamento total, 59 unidades na área de abastecimento de água, 57 na área do setor de esgotamento sanitário, 35 municípios na área do setor de manejo de águas pluviais e 57 unidades no manejo resíduos sólidos. Tais números representam menos de 15\% do Estado de São Paulo, transmitindo que a maioria da população passa por carências básicas dignas de regiões atrasadas e sem desenvolvimento.

Recentemente o governo do Estado de São Paulo propôs programas de instalação de rede de esgoto para trabalhadores que recebem até três salários mínimos. Pegando esta política pública como exemplo, emerge o questionamento: seria o saneamento, como item básico de condição de vida, derivativo de uma ação programada pelo governo para parte da população, ou seria direito de todos e dever da Instituição?

A variável Despesa com Urbanismo também mostrou-se significante na discriminação do IDHM e de acordo com o SEADE ${ }^{37}$, 95,9\% do Estado de São Paulo é urbanizado. Tal dado revela que os municípios têm condições de instalações de sistemas de saneamento, mas contradiz-se ao fato de que é a minoria que efetivamente investe, mas a maioria poderia investir.

Espera-se que variáveis que surtem impactos sociais sejam prioritárias nos investimentos (Assistência Social, Educação, Saneamento e Saúde) visto que o desenvolvimento de uma região principia do desenvolvi-

35 INSTITUTO TRATA BRASIL. Situação do saneamento no Brasil. Disponível em: <http://www.tratabrasil.org.br/situacao-dosaneamento-no-brasil>. Acesso em: 15 abr. 2014.

36 INSTITUTO BRALISEIRO DE GEOGRAFIA E ESTATÍSTICA. Pesquisa Nacional de Saneamento Básico 2008. Disponível em: <http://www.ibge.gov.br/estadosat/temas.php?sigla=sp\&tema=saneamentobasico2008>. Acesso em: 15 abr. 2014.

37 FUNDAÇÃO SEADE. Seade 35 anos: estatísticas públicas para o desenvolvimento do Estado de São Paulo. Disponível em: <http://www.seade.gov.br/wp-content/uploads/2014/12/Seade-35-anos-PDF.pdf>. Acesso em: 01 dez. 2013. 
mento de sua população. Em média, as variáveis Despesa com Educação e Despesa com Saúde apresentam os valores mais altos de investimentos. Porém, notou-se que a variável Despesa com Saúde não discrimina o índice de desenvolvimento humano municipal. Se cruzarmos os dados de investimentos em saúde e saneamento, de acordo com a Organização Mundial da Saúde, 2004, a cada R \$1,00 investido em saneamento, R \$ 4,00 são economizados na área da saúde, então, arrisca-se afirmar a vantagem desse investimento que traz retorno à qualidade de vida da população e à economia do governo, sendo o saneamento, um item primordial para evitar alguns tipos de doenças.

Observando-se o cenário da Educação, de acordo com o $\mathrm{IBGE}^{38}$, a população residente do Estado de São Paulo totaliza 41.262.199 pessoas. Desse número, 14.974.003 é representado por pessoas de 10 anos ou mais de idade, sem instrução e fundamental incompleto, ou seja, 36,3\% da população e, 8.447.883 representam as pessoas de 10 anos ou mais de idade que frequentavam a escola, 20,5\% da população residente. Conclui-se, a partir dos dados, que é maior a porcentagem de população sem educação no Estado. Supõe-se, com base na análise proposta neste estudo, que a população que teve acesso à Educação concentra-se nos municípios mais desenvolvidos (Grupo 2) e que, o Grupo 1 tende a investir no setor para reverter e diminuir o total de pessoas sem acesso à instrução.

Assim, ainda que as conclusões deste estudo contemplem apenas a amostra do Estado de São Paulo, elas evidenciam a necessidade de maior estudo e estratégia por parte dos administradores públicos nas tomadas de decisões para direcionar as políticas de acordo com a situação do município em seu cenário específico. Arrisca-se ainda, que municípios menos desenvolvidos devem investir no bem-estar de sua população (principiando pelo setor de saneamento, enfatizado neste estudo) e apostar em projetos que tragam benefícios ampliados afinal, como já citado, a despesa estratégica em determinado setor, pode surtir efeito em outros, aumentando as chances de acerto e satisfação.

\section{REFERÊNCIAS}

ADEYEMI, Sidikat L. et al. Determinants of human development in Sub-Saharan Africa. African Journal of Economic Policy, Africa, v. 13, n. 2, p. 15-34, dec. 2006.

AKDER, Halis. A means to closing gaps: disaggregated human development index Human Development. New York: UNDP, 1994. (Report Office Occasional Papers, 18).

ALVES JÚNIOR, José A. O impacto das receitas no Índice de Desenvolvimento Humano (IDH) dos municípios do Estado do Ceará. 2004. 72 f. Dissertação (Mestrado) - Programa de pós-graduação em Economia, Faculdade de Economia, Universidade Federal do Ceará, Fortaleza, 2004.

ANGELO, Lícia de Cerqueira et al. Fatores explicativos do Índice de Desenvolvimento Humano (IDH) para os municípios de Alagoas. Economia política do desenvolvimento, Maceió, v. 1, n. 6, p. 31-47, set./dez. 2009.

BARROS, Ricardo Paes de et al. O Índice de Desenvolvimento da Família (IDF): Rio de Janeiro: IPEA, 2003. (Texto para discussão, 98).

EPHERENESIS, Dag. Policy uses of HDI: goals and strategies. SIDA: Planeringssekretariatet, 1994.

FARINA, Milton Carlos; GOUVÊA, Maria Aparecida; VARELA, Patrícia Siqueira. A diferenciação dos Grupos 2 e 5 de municípios paulistas, segundo o IPRS, a partir das transferências constitucionais e das receitas tributárias: uma aplicação de análise discriminante. Revista Contemporânea de Economia e Gestão, Fortaleza, v. 5, n. 1, p. 17-28, jan./jul. 2007.

38 INSTITUTO BRALISEIRO DE GEOGRAFIA E ESTATíSTICA. Pesquisa Nacional de Saneamento Básico 2008. Disponível em: <http://www.ibge.gov.br/estadosat/temas.php?sigla=sp\&tema=saneamentobasico2008>. Acesso em: 15 abr. 2014. 
FUNDAÇÃO JOÃO PINHEIRO. Disponível em: <www.fjp.mg.gov.br>. Acesso em: 01 dez. 2013.

FUNDAÇÃO SEADE. Seade 35 anos: estatísticas públicas para o desenvolvimento do estado de São Paulo. Disponível em: <http://www.seade.gov.br/wp-content/uploads/2014/12/Seade-35-anos-PDF.pdf>. Acesso em: 01 dez. 2013.

HAIR JÚNIOR, J.F. et al. Análise multivariada de dados. 5. ed. Porto Alegre: Bookman, 2005.

HOPKINS, Michael. Human Development Revisited: a new UNDP report. World Development, v.19, n. 10, 1991.

INSTITUTO BRALISEIRO DE GEOGRAFIA E ESTATÍSTICA. Pesquisa Nacional de Saneamento Básico 2008. Disponível em: <http://www.ibge.gov.br/estadosat/temas.php?sigla=sp\&tema=saneamentobasi co2008>. Acesso em: 15 abr. 2014.

INSTITUTO TRATA BRASIL. Situação do saneamento no Brasil. Disponível em: < http:/ / www.tratabrasil.org. br/situacao-do-saneamento-no-brasil>. Acesso em: 15 abr. 2014.

IVANOVA, Ianita M. SRINIVASAN, G.; ARCELUS, F. J. A Quantitative measure of the competitive advantage of nations. New Brunswick: University of New Brunswick, 1994. (Working paper series, n. 94-008).

IVANOVA, Ianita M.; ARCELUS, F. J.; SRINIVASAN, G. Effects of the Human Development Index's Social and Economic Components of Country Rankings. New Brunswick: University of New Brunswick, 1994.

KANBUR, Ravi. Poverty and development: the human development report and the world development report 1990. Coventry: University of Warwick, 1990. (Discussion Paper, 103).

KILSZTAJN, Samuel. Paridade do poder de compra, renda per capita e outros indicadores econômicos. Revista Pesquisa e Debate, São Paulo, v. 11, n. 2, p. 93-106, 2000.

KURT, Serdar; SAVRUL, Mesut. The effect of the European Union on human development. International Research Journal of Finance and Economics, United Kingdom, v. 65, p. 35-42, 2011.

NASCIMENTO, Cleyber et al. IDHM de 2010 do Ceará. Boletim IPECE, Fortaleza, n. 62, ago. 2013.

Disponível em: <http://www.ipece.ce.gov.br/publicacoes/ipece-informe/Ipece_Informe_62_13_agosto_2013.pdf>. Acesso em: 15 abr. 2014

PREARO, Leandro Campi. O uso de técnicas multivariadas em dissertações e teses sobre o comportamento do consumidor: um estudo exploratório. 2008. 100 f. Dissertação (Mestrado) - Programa de Pós-graduação em Economia. Faculdade de Economia, Administração e Contabilidade, Universidade de São Paulo, São Paulo, 2008

PREARO, Leandro Campi. Os serviços públicos e o bem-estar subjetivo da população: uma modelagem multigrupos baseada em mínimos quadrados parciais. 2013. 257 f. Tese. (Doutorado) - Programa de Pós-graduação em Economia, Faculdade de Economia, Administração e Contabilidade, Universidade de São Paulo, São Paulo, 2013.

PROGRAMA DAS NAÇÕES UNIDAS PARA O DESENVOLVIMENTO. Atlas do desenvolvimento bumano dos municípios. Disponível em: < http://www.pnud.org.br/IDH/Default.aspx?indiceAccordion=1\&li=li_AtlasMunicipios>. Acesso em: 01 dez. 2013.

PROGRAMA DAS NAÇÕES UNIDAS PARA O DESENVOLVIMENTO. Atlas do Desenvolvimento Humano, 2013. Disponível em: <http://www.pnud.org.br/IDH/EntendaAtlas.aspx?indiceAccordion=1\&li=li_ Entenda>. Acesso em: 07 dez. 2013.

PROGRAMA DAS NAÇÕES UNIDAS PARA O DESENVOLVIMENTO. Nosso trabalho. Disponível em: <http://www.pnud.org.br/NossosProjetos.aspx>. Acesso em: 01 dez. 2013.

PROGRAMA DAS NAÇÕES UNIDAS PARA O DESENVOLVIMENTO. O que é o IDHM. Disponível em: < http://www.pnud.org.br/IDH/IDHM.aspx?indiceAccordion=0\&li=li_IDHM>. Acesso em: 07 dez. 2013. 
PYATT, Graham. There is nothing wrong with the HDI but. England: University of Warwick, 1992.

RAMIREZ, Alejandro; RANIS, Gustav; STEWART, Frances. economic growth and human development. New Haven: Yale University, dec. 1997. (Center Discussion Paper, n. 787).

RAZMI, Mohammad Javad; ABBASIAN, Ezatollah; MOHAMMADI, Sahar. Investigating the effect of government health expenditure on HDI in Iran. Journal of Knowledge Management, Economics and Information Technology, Iran, v. 5, p. 119-131, oct. 2012.

REZENDE, Amaury José; SLOMSKI, Valmor; CORRAR, Luiz João. A gestão pública municipal e a eficiência dos gastos públicos: uma investigação empírica entre as políticas públicas e o Índice de Desenvolvimento Humano (IDH) dos municípios do Estado de São Paulo. Revista Universo Contábil, Blumenau, v. 1, n. 1, p 24-40, jan./abr. 2005.

RYTEN, Jacob. Should there be a buman development index. Montreux: Internacional Association for Official Statistics, sept. 2000.

SANTOS, Manuel Roque Dos; DIAS, José Maria; FERNANDES, Gilênio Borges. Avaliação da Capacidade de Predição de Índice de Desenvolvimento Humano dos Municípios (IDHM) a partir das Demonstrações Contábeis Legais. In: ENCONTRO DA ANPAD, 34., 2010, Rio de Janeiro. Anais...Rio de Janeiro: ANPAD, 2010.p. 1-17.

SHOME, Swaha; TONDON, Sakira. Balancing human development with economic growth: a study of ASEAN 5. Annals of the University of Petroşani, Petroşani, v. 10, n. 2, p. 335-348, 2010.

SILVA, Lara Lúcia da, et al. A influência do desempenho tributário e gestão fiscal no Índice Firjan de Desenvolvimento (IFDM) dos municípios de Minas Gerais. Revista de Ciências Humanas, Viçosa, v. 13, n. 1, p. 199- 219, jan./jun. 2013. 
Para publicar na revista Brasileira de Políticas Públicas, acesse o endereço eletrônico www.rbpp.uniceub.br

Observe as normas de publicação, para facilitar e agilizar o trabalho de edição. 